\title{
Study of Quantitative Model for Maslow's View of Humanity Happiness
}

\author{
Yaoyao Wei1,2, Tian Xie ${ }^{1 *}$, Yuxiang Hong3 \\ ${ }^{1}$ School of Economics \& Management, University of South China, Hengyang, China \\ ${ }^{2}$ School of Political Science and Public Administration, University of South China, Hengyang, China \\ ${ }^{3}$ School of Management, Hangzhou Dianzi University, Hangzhou, China \\ Email: "thanksky709394@163.com
}

Received 24 March 2016; accepted 19 April 2016; published 22 April 2016

Copyright (C) 2016 by authors and Scientific Research Publishing Inc.

This work is licensed under the Creative Commons Attribution International License (CC BY).

http://creativecommons.org/licenses/by/4.0/

(c) (i) Open Access

\begin{abstract}
Maslow's view of Humanity Happiness argues that people feel happy when their needs are satisfied in a certain level. For exploring the quantitative evaluation methods of humanity happiness, firstly, based on the theories of Humanity Happiness and Fuzzy Sets, the concept "need-satisfied membership" is proposed to describe subjective feelings of individual happiness quantitatively. Secondly, a comprehensive happiness membership indicator system is constructed. Its indicator weights can be computed based on Analytic Hierarchy Process (AHP) method. And then the individual comprehensive happiness can be analyzed quantitatively. Furthermore, the general happiness membership function model as a more scientific measurement method is proposed for quantitatively analyzing the happiness of specific people in specific areas.
\end{abstract}

\section{Keywords}

\section{Need, Humanity Happiness, Membership, Quantitative Model}

\section{Introduction}

Hierarchy of needs and humanistic psychology teach us that the happiness degrees are determined by the satisfaction degrees about people's different needs. This humanistic view of happiness, which takes the satisfactions of individual needs as key value orientations, presents qualitative logic for think about happiness. However, without a quantitative method for measuring the need-satisfied levels, it is difficult to analyze and evaluate the social happiness views accurately. Therefore, based on Humanistic Happiness View, Fuzzy Set and AHP, the quantifying methods, which are able to reflect the individual and (regional) social happiness views, are proposed

\footnotetext{
${ }^{*}$ Corresponding author.
} 
in this paper [1].

\section{Views of Hierarchy of Needs and Humanity Happiness}

Aristotle believes that distinguishing from other animals, human are the only ones who can feel and understand happiness. It also means that happiness is human's exclusive nature (Miller, 2011). So what is happiness? And how can it be obtained? Maslow thinks that human needs are created and satisfied constantly, and people feel happy in the satisfying processes. Therefore, to understand needs is important to understand happiness.

Maslow argues that from low physical need to high spiritual needs, there are five need levels of people. The first level consists of the physiological needs such as food, clothing, shelter, health, reproduce. The second level consists of safety needs such as health, social security, environment security. The third level consists of Affiliation needs such as family, friendships, and social relationships. The fourth level consists of Esteem needs such as honor, social position, job position. The fifth or the top level consists of self-fulfillment needs such as selfaffirmation, ideal realization.

Viewing from the point of fundamental needs of people, Maslow explored the inherent relationships between needs and happiness, and argued that the satisfaction of needs is happiness (Pettijohn, 1996). And then the relevant theories developed from Hierarchy of needs to Hierarchy of happiness including the views as follows: firstly, individual happiness is determined by the satisfaction degree of the need at the same level. Secondly, although the needs always cannot be satisfied completely, when some thresholds of satisfaction degrees are achieved, people feel happy. Thirdly, only when the physical needs in lower level are satisfied, the spiritual needs in higher level generate. And then people will pursuit of happiness in higher level only when the lower happiness achieved to some extent. Fourth, in some specific situations, priority needs determine people's primary motivations. Therefore, the happiness of satisfying the priority needs would be achieved first. For example, water and foods are priority needs of a hungry man in desert, and his primary motivation is to look for water and foods. However, if he found an oasis full of water and foods, his physiological needs will be satisfied quickly, and he will feel a temporarily happy in the sense. After that, the safety needs become the new priority needs, and looking for a dwelling to achieve safety happiness becomes the new primary task.

People's motivations and actions are triggered by Needs. However, how well can the needs be satisfied, or how happy can be achieved by relevant actions? It is difficult to consider this question accurately only by subjective perceiving. And the key to this puzzle is to quantify the need satisfaction degree.

\section{Quantitative Method of Humanity Happiness Based on Needs-Satisfied Membership}

The need satisfaction degrees always depend on people's subjective assessments. However, in the actually activities such as consuming or working, people's subjective feelings are easily influenced by some complex factors such as their own preference, value view, environment. Therefore, subjective assessments are too ambiguous and unscientific to describe and control accurately. As exemplified above, after eating and drinking in the oasis, the man felt "quite full". Then he found a habitable cave, and felt "quite safe". Because the concept of "quite" is too ambiguous along with the different dimensions, it is hard to calculate the need-satisfied degrees for comparing his physiology happiness with safety happiness. To solve this problem, we try to represent the individual subjective need-satisfied (happiness) degrees based on the methods of Membership Function of Fuzzy Sets [2] and the Satisfaction Scale of Psychology [3].

Membership degree is an effective method for quantifying and evaluating based on Fuzzy Sets. For any element " $x$ " of a domain " $U$ ", if there is a relevant number " $A(x) \in[0,1]$ ", " $A$ " is a fuzzy set of " $U$ ", and " $A(x)$ " is the membership degree of " $x$ belongs to $A$ ". And if " $x$ " is a variable, " $A(x)$ " is a membership function. The value range of membership function is " $[0,1]$ ". It means that the closer the membership " $A(x)$ " is to 1 , the more " $x$ " belongs to " $A$ ". Otherwise, the closer the membership is to 0 , the less " $x$ " belongs to " $A$ ". Therefore, based on the objective need indicators of the Hierarchy of Needs, the subjective and ambiguous satisfaction degrees of people can be mapped into the unified non-dimensional membership scale for achieving the quantification processes of happiness.

To measure the subjective need-satisfied degrees, the interest examination scale is introduced. The interest examination scale is a psychology method which is used to examine personal indicators such as the characteristic and interest for giving some appropriate advices. Actually, it is a behavior or thing choosing process. Distin- 
guishing from this process, we use the scale to quantify and calculate the subjective need-satisfied (happiness) degrees. And then by designing the happiness satisfaction degree scale, the membership function values can be obtained directly (due to the limit of space, only abbreviated scale is shown as Table 1).

The detail quantifying principle is shown in Figure 1, firstly, according to the hierarchy of needs, design relevant need-satisfied examination questions for obtaining the subjective feelings of people from different social groups. And a 9-level valuation criteria including "completely unsatisfied, extremely unsatisfied, very unsatisfied, unsatisfied, no feeling, satisfied, very satisfied, extremely satisfied, completely satisfied" is set for describing the relevant satisfaction degrees respectively. Secondly, based on the membership function method of Fuzzy Sets theory, build the mapping relationships between the 9-level criteria and membership functions. Setting membership " $A$ (completely satisfied) $=1$ " means that a need is completely satisfied, and its relevant happiness membership degree is 1 . And setting membership " $A$ (completely unsatisfied) $=0$ " means that a need is completely unsatisfied, and its relevant happiness membership degree is 0 . Similarly, the rest of happiness membership degrees can be set as " $A$ (extremely satisfied) $=0.875, A$ (very satisfied) $=0.75, A$ (satisfied) $=0.625, A$ (satisfied $)=0.5, A$ (no feeling $)=0.5, A$ (unsatisfied $)=0.375, A$ (very unsatisfied $)=0.25, A$ (extremely unsatisfied $)$ $=0.125$ ". Based on the operations above, the people's subjective happy feelings can be transformed into the membership values in the range of $[0,1]$ quantitatively. And with that unified non-dimensional values, the comprehensive analyzing and calculating processes for happiness views of different groups can be implemented effectively.

\section{Comprehensive Membership Function Model}

Every happiness membership degree transformed from subjective need-satisfied feeling is a quantifying result of

Table 1. Abbreviated scale of happiness satisfaction degree.

\begin{tabular}{|c|c|c|}
\hline $\begin{array}{l}\text { First-class } \\
\text { targets }\end{array}$ & $\begin{array}{l}\text { Second-class } \\
\text { indicators }\end{array}$ & Subjective feelings \\
\hline \multirow{3}{*}{$\begin{array}{l}\text { Physiology } \\
\text { needs }\end{array}$} & $\begin{array}{l}\text { Food, breathe, } \\
\text { water... }\end{array}$ & $\begin{array}{l}\text { 1) completely unsatisfied; 2) extremely unsatisfied; 3) very unsatisfied; 4) unsatisfied; 5) no } \\
\text { feeling; 6) satisfied; 7) very satisfied; 8) extremely satisfied; 9) completely satisfied }\end{array}$ \\
\hline & Shelter & $\begin{array}{l}\text { 1) completely unsatisfied; 2) extremely unsatisfied; 3) very unsatisfied; 4) unsatisfied; 5) no } \\
\text { feeling; 6) satisfied; 7) very satisfied; 8) extremely satisfied; 9) completely satisfied }\end{array}$ \\
\hline & Reproduce & $\begin{array}{l}\text { 1) completely unsatisfied; 2) extremely unsatisfied; 3) very unsatisfied; 4) unsatisfied; 5) no } \\
\text { feeling; 6) satisfied; 7) very satisfied; 8) extremely satisfied; 9) completely satisfied }\end{array}$ \\
\hline$\cdots$ & $\cdots$ & $\ldots \ldots$ \\
\hline \multirow{2}{*}{$\begin{array}{l}\text { Self-fulfillment } \\
\text { needs }\end{array}$} & Self-affirmation & $\begin{array}{l}\text { 1) completely unsatisfied; 2) extremely unsatisfied; 3) very unsatisfied; 4) unsatisfied; 5) no } \\
\text { feeling; 6) satisfied; 7) very satisfied; 8) extremely satisfied; 9) completely satisfied }\end{array}$ \\
\hline & Ideal realization & $\begin{array}{l}\text { 1) completely unsatisfied; 2) extremely unsatisfied; 3) very unsatisfied; 4) unsatisfied; 5) no } \\
\text { feeling; 6) satisfied; 7) very satisfied; 8) extremely satisfied; 9) completely satisfied }\end{array}$ \\
\hline
\end{tabular}

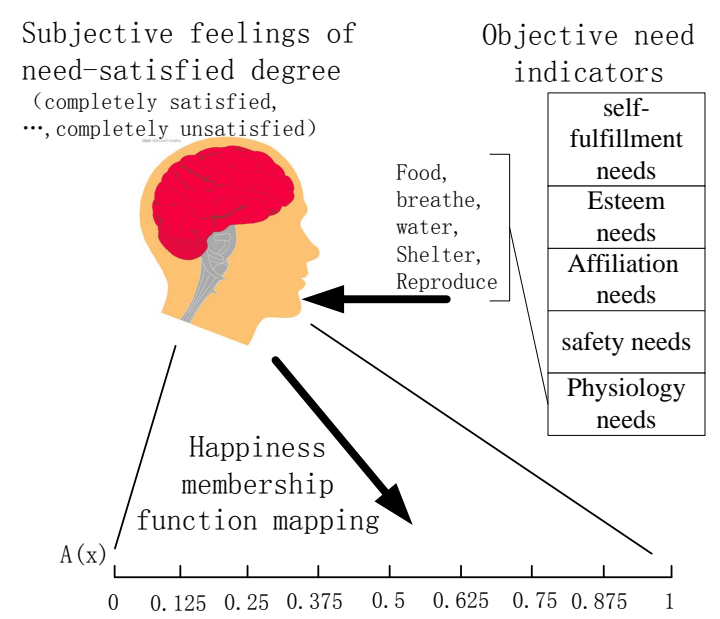

Figure 1. Humanity happiness quantifying principle based on need-satisfied membership degrees. 
partial need indicators. As exemplified above, after eating, the hungry man feels very full, and then the happiness membership value is 0.75 . However, it only can reflect the happiness degree about his food need rather than all of his needs in that moment. Additionally, a happiness membership degree can not reflect the integrated happiness views supported by various people in an area. Therefore, considering both the universality and comprehensiveness, and building a comprehensive humanity happiness membership model are also important.

\subsection{Individual Happiness Membership Function Model}

1) Hierarchy indicator system of individual comprehensive happiness membership.

According to the individual, the different happiness indicator shows different importance in his comprehensive happiness membership degrees. We set the weight coefficients of each indicator to represent the importance of them respectively. By the way, according to Humanity Happiness four views (shown in the section 1 of this paper), although everyone has his own opinions about the importance of the happiness indicators, it is not hard to know that the basic lower-level happiness should be more important than the high-level happiness. And then the relevant indicators of former should be given more weights.

Referenced to the Hierarchy needs model [1], the Hierarchy Indicator System of Individual Comprehensive Happiness Membership (HISICHM) is constructed as Figure 2. For individual $i$, his comprehensive happiness membership function is:

$$
a_{i}(x)=\sum \omega_{i j k} a_{i}\left(x_{j k}\right), \quad(i=1,2, \cdots, n ; j=1,2,3,4,5 ; k=1,2,3 \cdots)
$$

In this formula, $a_{i}\left(x_{j k}\right)$ denotes the happiness membership value for happiness indicator of class $k$ of level $j$ of HISICHM. And $\omega_{i j k}$ denotes the weight value for happiness indicator of class $k$ of level $j$ of HISICHM. For every level, $\sum \omega_{i j k}=1$.

2) Determining the weights of the happiness membership indicators.

AHP is a combination of qualitative and quantitative methods. And the experts can use the AHP to quantify the evaluation processes of indicator's importance and to determine the weight $w_{i j k}$. There are some mature and efficient tools for solving the AHP models, such as "Expert Choice". And by real-time consistency checks, the accuracy and rationality of the evaluation processes can be improved.

The principle of AHP includes [4]: firstly, by analyzing the relationships of the indicators, the HISICHM is constructed as shown in Figure 2. Secondly, based on the methods of expert investigation, the pairwise importance comparison processes are implemented between the indicators of the same level to construct the judgment matrixes. Thirdly, after calculating the matrixes based on the algorithm of root method, the weights of the indicators can be obtained respectively.

\subsection{General Happiness Membership Function Model for Groups in an Area}

Because the differences of the happiness feelings are relevant with the factors of individual knowledge structure, social position, income and so on, the happiness feelings are different from group to group in the same area [5]. Therefore, the weighted average method can be used for representing the general happiness membership for various groups in an area.

$$
a=\sum_{l=1}^{m} \omega_{l}\left(\frac{1}{n} \sum_{i=1}^{n} a_{i}(x)\right), \quad(i=1,2, \cdots n ; l=1,2, \cdots, m)
$$

In this formula, $m$ denotes the number of groups. If we take the educational background (such as primary school graduate, high school graduate, bachelor's degree, postgraduate) as the group standard, the value of $m$ is 4 . And $w_{j}$ denotes the weight of the average happiness membership of group l. After considering both the number of people and social influence of the groups respectively, the weight value can be given by some seasoned and authoritative experts. And $\mathrm{n}$ denotes the number of people of each group.

There are three steps in the model implement process: firstly, obtaining the individual need-satisfied feelings with the scale (Table 1). And the individual happiness membership $a_{i}\left(x_{j k}\right)$ of every indicator of HISICHM can be transformed from the relevant feelings based on the principle shown in Figure 1. Secondly, after calculating the value of weight $\omega_{i j k}$ based on AHP method, the individual comprehensive happiness membership $a_{i}(x)$ can also be calculated with formula (1). Finally, based on the weights of happiness memberships of various groups, the general happiness memberships $a$ can be calculated with formula (2). 


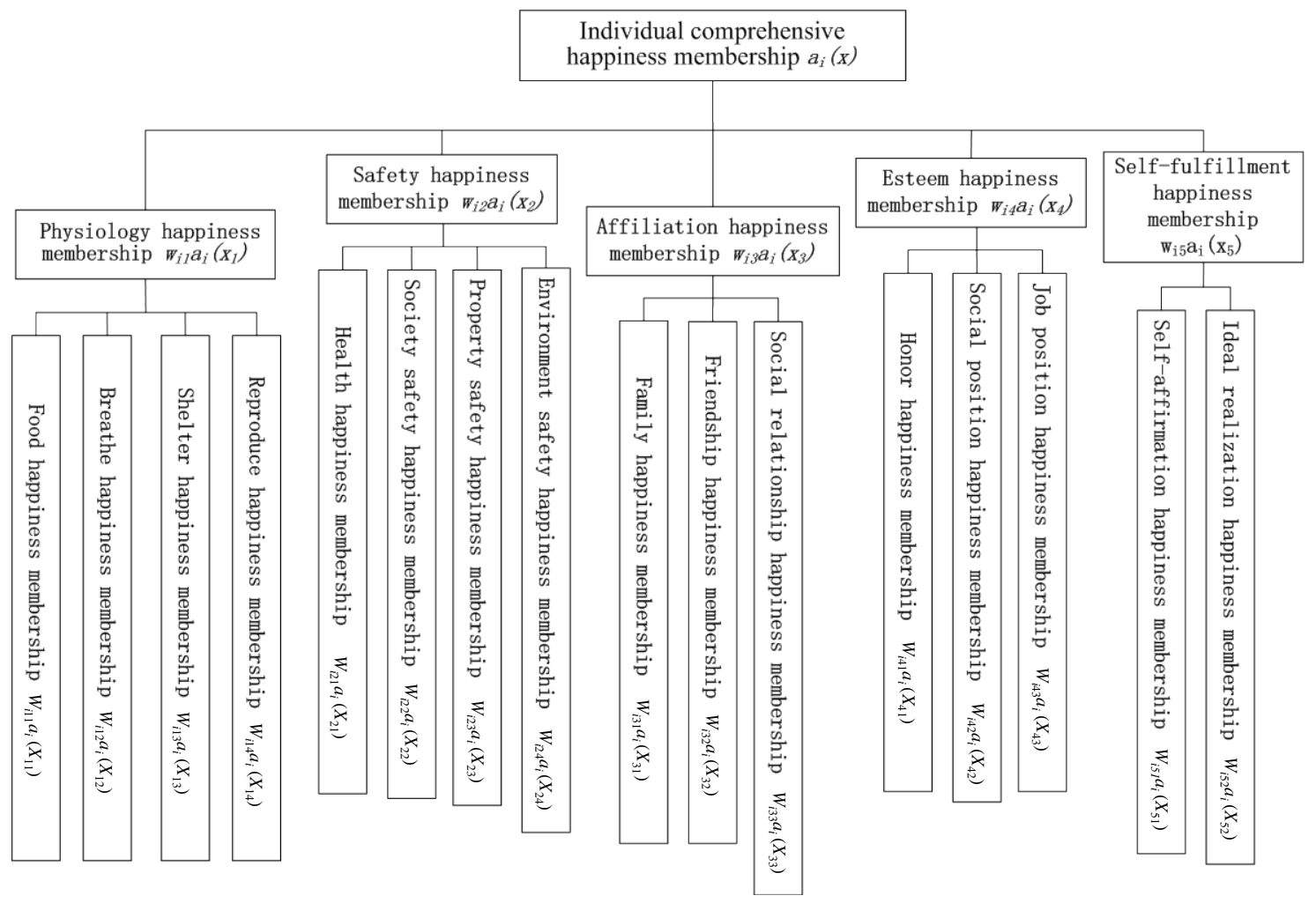

Figure 2. Hierarchy indicator system of individual comprehensive happiness membership.

\section{Conclusions}

Maslow believes that happiness is some feelings of need satisfactions. However, only the qualitative hierarchical logic is presented by his Humanity Happiness view. In this paper, for measuring the general happiness views of people accurately and comprehensively, firstly, based on Theories of Humanity Happiness and Fuzzy Sets, a happiness needs-satisfied membership quantifying method, which can transform individual subjective feelings into unified dimensional values, is proposed. Secondly, based on AHP, the membership function models of individual comprehensive happiness and general happiness view are presented for quantitatively analyzing the happiness of specific people in specific areas.

The quantitative model proposed in this paper is combination of qualitative and quantitative methods. Therefore it follows both social science study pattern and the subjective happy feelings. And then by quantitatively analyzing the general happiness memberships of groups from different industries, areas, social positions, and educational backgrounds, the general and social happiness views, which are helpful for learning current state of society and providing some scientific basis for social stability and harmony, can be concluded.

\section{Acknowledgements}

The paper is supported by Young Foundation of National Natural Science Foundation of China (No. 71501087), Young Foundation of Ministry of Education of China (No. 14YJCZH168), and the research is also supported by the Key Discipline of Management Science and Engineering of USC.

\section{References}

[1] Maslow, A.H. (1967) A Theory of Metamotivation: The Biological Rooting of the Value-Life. Journal of Humanistic Psychology, 7, 93-127. http://dx.doi.org/10.1177/002216786700700201

[2] Zadeh, L.A. (1965) Fuzzy Sets. Information \& Control, 8, 338-353. http://dx.doi.org/10.1016/S0019-9958(65)90241-X

[3] Rackow, P., Scholz, U. and Homung, R. (2013) The German Psychological Need Satisfaction in Exercise Scale: Validation of a Measure of Need Satisfaction in Exercise. Swiss Journal of Psychology, 72, 137-148. 
http://dx.doi.org/10.1024/1421-0185/a000107

[4] Su, X., Mahadevan, S., Xu, P. and Deng, Y. (2015) Dependence Assessment in Human Reliability Analysis Using Evidence Theory and AHP. Risk Analysis, 35, 1296-1316. http://dx.doi.org/10.1111/risa.12347

[5] Cuñado, J. and Gracia, F.P.D. (2012) Does Education Affect Happiness? Evidence for Spain. Social Indicators Research, 108, 185-196. http://dx.doi.org/10.1007/s11205-011-9874-x 